\title{
Effects of Capparis decidua Hydroalcoholic Extracts on Blood Glucose, Lipid Profile and Leptin of Wistar Male Rats with High Cholesterol Diets
}

\author{
Mohammad Reza Shahraki ${ }^{1}$, Fereshteh Badini ${ }^{2}$, Elham Shahraki ${ }^{3}$, Ahmad Reza Shahraki ${ }^{4}$, Ali Reza Dashipoure $*^{5}$ \\ 1- Physiology Department, Faculty of Medicine, Zahedan university of Medical Sciences and Health Services, Zahedan, Iran \\ 2- MSc of Animal Physiology, Department of Biology, Faculty of Science, Payame Noor University, Tehran, Iran \\ 3- Assistant professor of Nephrology, Emam Ali Hospital, Department of internal Medicine, Faculty of Medicine, Zahedan University of Medical \\ Sciences and Health Services, Zahedan, Iran \\ 4- Resident of General Surgery, Zahedan University of Medical Sciences and Health Services, Zahedan, Iran \\ 5- Department of Food Science and Nutrition, School of Medicine, Cellular and Molecular Research Center, Zahedan University of Medical Sciences \\ and Health Services, Zahedan, Iran
}

\section{A B S T R A C T}

Background and Objectives: Capparis decidua is a plant used in herbal medicine. This study was carried out to assess effects of $C$. decidua hydroalcoholic extract on blood glucose, lipid profile and leptin in male rats with high-cholesterol diets.

Materials and Methods: Totally, 40 Wistar-albino male rats with 200-250 g weight were equally divided into one control (C) and three experimental groups of high-cholesterol diet (HCD), high-cholesterol diet and lovastatin (HCDL) and high-cholesterol diet and C. decidua hydroalcoholic extract (HCDCD). At the end of the intervention, animals were sacrificed using deep anesthesia. Blood samples were collected and fasting blood sugar (FBS), high density lipoprotein (HDL), total cholesterol (TC), triglycerides (TG) and leptin were assessed. Low density lipoprotein (LDL) was calculated using Friedewald formula. Results were expressed as mean $\pm \mathrm{SE}$ (standard error). The $P<0.05$ was considered as statistically significant.

Results: Serum TG in HCDCD group significantly decreased, compared to C and HCD groups $\left(71.33 \pm 3.55\left(\mathrm{mg} \mathrm{dl}^{-1}\right)\right.$ instead of $97.55 \pm 7.09\left(\mathrm{mg} \mathrm{dl}^{-1}\right)$ and $94 \pm 7.01\left(\mathrm{mg} \mathrm{dl}^{-1}\right)$ respectively, $\left.P=0.003\right)$ and TC in HCDCD group significantly decreased, compared to HCD group $\left(67.66 \pm 2.65\left(\mathrm{mg} \mathrm{dl}^{-1}\right)\right.$ instead of $\left.83.11 \pm 5.25\left(\mathrm{mg} \mathrm{dl}^{-1}\right), P=0.021\right)$. Moreover, TC in HCDL group significantly decreased, compared to HCD group $\left(68.33 \pm 1.88\left(\mathrm{mg} \mathrm{dl}^{-1}\right)\right.$ instead of $83.11 \pm 5.25\left(\mathrm{mg} \mathrm{dl}^{-1}\right), P=$ 0.04). Leptin included the lowest value in HCDL group, compared to other groups $(P<0.0001)$. Other parameters did not include significant differences within the groups.

Conclusions: The current findings have demonstrated that hydroalcoholic extracts from $C$. decidua leaves and thin stems decreased serum TG and TC in HCDCD male rats.

Keywords: Capparis decidua, High cholesterol diet, Lipid profile, Leptin, Wistar rat

\section{Introduction}

Nowadays, preference of using medicinal plants is increasing because they are widely available, usually include less side effects and are relatively inexpensive (1). Capparis decidua is a traditional plant, which grows in western parts of India and Pakistan and in Southern Iran, including Hormozgan and Baloochestan $(2,3)$. This herbal medicine is locally known as Kalir and grows in semi dry regions. The plant hydroalcoholic extract administration in rats is safe and includes therapeutic effects (4-6). Traditionally, $C$. decidua is used to relieve inflammation, rheumatism and distension $(7,8)$. The plant fruits are used in food preparation and include antidiabetic, hypolipidemic and antioxidant properties. Zia-Ul-Haq et al. (2011) demonstrated that C. decidua fruits and seeds that used in urinary infections included diuretic and antidiabetic properties $(8,9)$. Cardiovascular diseases (CVD) are 
now of the leading death causes in men and women. Diabetes mellitus associated with impaired insulin function, hyperglycemia and hyperlipidemia are important factors in increasing CVD (10). Adipose tissues are storages for the fats and include central roles in lipid and carbohydrate metabolisms (11). High-fat diets (HFD) induce fat deposition in adipose tissues in obese rats (12). Xue Q et al. (2018) showed that parental HFD was base of myocardial variations and altered blood pressures in fetal and neonatal rats (13). Furthermore, HFD and high-carbohydrate diets can induce hepatic fatty acid production and lipogenesis in mice $(14,15)$. Leptin includes a critical role in energy homeostasis. The chemical is a polypeptide hormone and is secreted by the adipose tissues. Leptin deficiency causes hyperphagia and induces obesity in humans and animals $(16,17)$. Excessive consumption of fat alters lipid profile and metabolism and acts as a risk factor for various diseases such as fatty liver, hypertension, hyperlipidemia and arteriosclerosis (18). Reseland et al. (2001) showed that plasma leptin was linked to dietary consumption of fats and long-term consumption of unsaturated lipids in humans (19). Based on previous reports on antihyperlipidemic and antidiabetic effects of $C$. decidua, the present study was carried out to assess effects of leave and thin stem hydroalcoholic extracts of $C$. decidua on blood sugar, lipid profile and leptin in male rats fed on highcholesterol diets (HCD).

\section{Materials and Methods}

\section{Animals}

The present study was carried out on 40 Wistaralbino male rats weighing 200-250 g and aging ten weeks. They were hosted in polypropylene cages under controlled conditions. The animals had free access to water and food. After one week of acclimation, rats were randomly divided into four groups $(n=10)$ and individually housed under controlled temperature $\left(23{ }^{\circ} \mathrm{C} \pm 2\right), 12$-h light-dark cycle (6 AM to $6 \mathrm{PM}$ ) and humidity (45-65\%).

\section{Animal groups}

Group C (control) received standard rodent chow and $2 \mathrm{ml} \mathrm{kg}^{-1}$ of methyl cellulose solution $(0.5 \%)$ using gavage for six weeks. Group HCD received 10 $\mathrm{mg} \mathrm{g}^{-1}$ of diet cholesterol and $2 \mathrm{ml} \mathrm{kg}^{-1}$ of methyl cellulose solution $(0.5 \%)$ using gavage for six weeks.
Group HCDL received $10 \mathrm{mg} \mathrm{g}^{-1}$ of diet cholesterol and lovastatin $\left(6 \mathrm{mg} \mathrm{kg}^{-1}\right)$ using gavage for six weeks. Group HCDCD received $10 \mathrm{mg} \mathrm{g}^{-1}$ of diet cholesterol and hydroalcoholic extracts $\left(300 \mathrm{mg} \mathrm{kg}^{-1}\right)$ of $C$. decidua leaves and thin stems using gavage for six weeks.

\section{Preparation of the extracts}

Leaves and thin stems of $C$. decidua were collected from a local area around Bampoure, southeast of Iran, in May 2018 and verified by the Biology Taxonomy Center of the Science Faculty, Sistan and Baluchestan University, Zahedan, Iran. Leaves and thin stems were separated, washed, isolated and shade-dried at room temperature and then powdered by hands (20). Totally, $50 \mathrm{~g}$ of the plant powder were suspended in $150 \mathrm{ml}$ of distilled water (D.W.) and $150 \mathrm{ml}$ of ethanol (96\%) and extracted using Soxhelet apparatus (H626 Model, Iran) for $7 \mathrm{~h}$. Extract was filtered using filter papers (Watman no.1) (21). Then, filtered extract was dried using incubator for three days at $37^{\circ} \mathrm{C}$ and stored $4^{\circ} \mathrm{C}$ until use.

\section{Preparation of high-cholesterol diets}

To prepare HCD, $1 \mathrm{~g}$ of cholesterol powder (Product No. C8667-25G; CAS No. 57_88_5; grad, > 99\%, MW, 386.65) (Sigma Aldrich, USA) was dissolved in $4 \mathrm{ml}$ of baking virgin olive oil (Ladan Gold, Iran) and added to $100 \mathrm{~g}$ of ordinary rodent food powder (Dam Pars, Iran). Tap water was added to the mixture to prepare dough and then pellets were prepared by drying dough at $45^{\circ} \mathrm{C}$ using oven.

\section{Blood biochemical tests}

At the end of the experiment (six weeks) and after an overnight fasting (12-14 h), all animals were deeply anesthetized using ketamine and xylazine (Merck, Germany) and sacrificed by decapitation. Blood samples were collected in test tubes and centrifuged at $3500 \times \mathrm{rpm}$ for $15 \mathrm{~min}$ at room temperature (21). Serum was separated using centrifuge (BH-1200 Type, Iran) and stored at $-70{ }^{\circ} \mathrm{C}$ until use. Fasting blood sugar (FBS), lipid profile including triglyceride (TG), high density lipoprotein (HDL) and total cholesterol (TC) were assessed immediately after sample preparation. The TG and HDL were assessed using precipitation of non-HDL lipoprotein with dextran/ $\mathrm{MgSO}_{4}$, followed by enzymatic cholesterol assay using Zist Shimi Kits, Iran, and standard methods adapted for RA 1000 Analyzer (Technicon, USA). The LDL was calculated 
according to Friedewald formula (22). Serum leptin was assessed using enzyme linked immunosorbent assay (ELISA) and specific rat leptin kit (Zell Bio $\mathrm{GmbH}$, Germany). Detection limit for rat leptin included $0.75-24 \mathrm{ng} \mathrm{ml}^{-1}$ and the sensitivity included $0.05 \mathrm{ng} \mathrm{ml}^{-1}$. All animal processes were carried out based on recommendations by Zahedan University of Medical Sciences Animal Care and international standards for the recruitment of experimental animals. An institutional ethics approval was received from the Committee for Animal Research, Zahedan University of Medical Sciences (Code of Ethics: IR.ZAUMS.REC.1396.199 No. 8483).

\section{Statistical analyses}

Data were reported as mean \pm SD (SEM). Data normality distribution was checked using Kolmogorov-Smirnov test. One-way analysis of variance (ANOVA) and Tukey post-hoc test were used to compare means within the groups. KruskalWallis test was used for data without normal distributions. Data were analyzed using SPSS Software v.17 (IBM Analytics, USA). The $P$-value was considered significant when calculated less than 0.05 .

\section{Results}

\section{Body weights}

As shown in Table 1, no significant differences were reported in initial body weight within the groups. Similar results were reported at the final weight of intervention (Week 6). No significant differences were seen in weight gain after six weeks of intervention within the groups.

\section{Cholesterol levels}

As shown in Table 2, TC level was significantly lower in HCDCD $\left(67.66 \pm 2.65\left(\mathrm{mg} \mathrm{dl}^{-1}\right)\right)$ and HCDL $\left(68.33 \pm 1.88\left(\mathrm{mg} \mathrm{dl}^{-1}\right)\right)$ groups, compared to that in HCD $\left(83.11 \pm 5.25\left(\mathrm{mg} \mathrm{dl}^{-1}\right)\right)$ group $(P=0.02)$. No significant differences were seen in TC level within HCDCD, HCDL and C $\left(74 \pm 4.14\left(\mathrm{mg} \mathrm{dl}^{-1}\right)\right)$ groups.

\section{Triglyceride levels}

As shown in Table 2, TG level in HCDCD group $\left.\left(71.33 \pm 3.55(\mathrm{mg} \mathrm{dl})^{-1}\right)\right)$ significantly decreased, compared to that in HCD $\left(94 \pm 7.01\left(\mathrm{mg} \mathrm{dl}^{-1}\right)\right)$ and C $\left(97.55 \pm 7.09 \quad\left(\mathrm{mg} \mathrm{dl}^{-1}\right)\right)$ groups. However, no significant differences were observed in TG level between the HCDCD and HCDL (75.77 \pm 3.12 (mg $\left.\mathrm{dl}^{-1}\right)$ ) groups (Table 2).

Table1. Effects of Capparis decidua hydroalcoholic extracts on serum FBS, HDL and LDL in high-cholesterol diets in male rats

\begin{tabular}{lccccc}
\hline & \multicolumn{4}{c}{ Group } \\
\cline { 2 - 5 } Parameter & $\mathrm{C}$ & HCD & HCDL & HCDCD & $P$-value \\
\hline Initial weight $(\mathrm{g})$ & $262.9 \pm 8.68$ & $276.2 \pm 10.74$ & $273.2 \pm 7.56$ & $278.3 \pm 1.74$ & 0.53 \\
Final weight $(\mathrm{g})$ & $302.3 \pm 12.35$ & $312.8 \pm 11.8$ & $301.3 \pm 7.8$ & $306.9 \pm 16.35$ & 0.82 \\
Weight gain after six weeks of intervention $(\mathrm{g})$ & $39.40 \pm 4.55$ & $36.60 \pm 17.72$ & $28 \pm 9.97$ & $28.60 \pm 4.40$ & 0.83 \\
\hline
\end{tabular}

Table2. Effects of Capparis decidua hydroalcoholic extracts on serum fasting blood sugar and lipid profile based on diets in male rats

\begin{tabular}{|c|c|c|c|c|c|}
\hline \multirow[b]{2}{*}{ Parameter } & \multicolumn{4}{|c|}{ Group } & \multirow[b]{2}{*}{$P$-value } \\
\hline & $\mathrm{C}$ & HCD & HCDL & HCDCD & \\
\hline FBS $\left(\mathrm{mg} \mathrm{dl}^{-1}\right)$ & $92.10 \pm 4.84$ & $93.50 \pm 5.26$ & $100.30 \pm 4.49$ & $99.90 \pm 3.87$ & 0.48 \\
\hline $\mathrm{TC}\left(\mathrm{mg} \mathrm{dl}^{-1}\right)$ & $74 \pm 4.14 a b c$ & $83.11 \pm 5.25 b$ & $68.33 \pm 1.88 \mathrm{c}$ & $67.66 \pm 2.65 c$ & 0.02 \\
\hline $\mathrm{TG}\left(\mathrm{mg} \mathrm{dl}^{-1}\right)$ & $97.55 \pm 7.09 \mathrm{a}$ & $94 \pm 7.01 \mathrm{a}$ & $75.77 \pm 3.12 b$ & $71.33 \pm 3.55 b$ & 0.003 \\
\hline HDL-C $\left(\mathrm{mg} \mathrm{dl}^{-1}\right)$ & $40.90 \pm 2.50$ & $46.60 \pm 2.44$ & $43.20 \pm 1.04$ & $41.20 \pm 1.11$ & 0.14 \\
\hline LDL-C $\left(\mathrm{mg} \mathrm{dl}^{-1}\right)$ & $14.98 \pm 3.53$ & $16.82 \pm 2.46$ & $10.24 \pm 2.06$ & $14.64 \pm 1.53$ & 0.31 \\
\hline
\end{tabular}

Data are expressed as mean \pm SEM. C, control group with standard chow and methyl cellulose solution (0.5\%) by gavage; HCD, standard chow mixed with 10 $\mathrm{mg} \mathrm{g}^{-1}$ of cholesterol and methyl cellulose solution $(0.5 \%)$ by gavage; HCDL, standard chow mixed with10 $\mathrm{mg} \mathrm{g}^{-1}$ of cholesterol and lovastatin $\left(6 \mathrm{mg} \mathrm{kg}^{-1}\right)$ by gavage; and HCDCD, standard chow mixed with $10 \mathrm{mg} \mathrm{g}^{-1}$ of cholesterol and $300 \mathrm{mg} \mathrm{kg}^{-1}$ of hydroalcoholic extracts from C. decidua leaves and thin stems by gavage. Different small letters in each row show significant differences within the groups (one-way ANOVA, $P<0.05, n=10$ ) 


\section{High-density lipoprotein (HDL) and low-density lipoprotein (LDL) levels}

Results showed no significant differences in HDL and LDL values within the groups (Table 2).

\section{Fasting blood sugar levels}

As shown in Table 2, no significant differences were seen in FBS level within the groups $(P>0.05)$.

\section{Leptin levels}

Figure 1 shows administration effects of hydroalcoholic extracts from $C$. decidua leaves and thin stems on leptin value. Results showed that leptin value decreased significantly in rats that fed with HCDL $\left(2.91 \pm 0.14\left(\mathrm{ng} \mathrm{dl}^{-1}\right), P<0.0001\right)$, compared to that leptin value did in other groups. No significant differences were seen in leptin values within control $\left(3.68 \pm 0.12\left(\mathrm{ng} \mathrm{dl}^{-1}\right)\right)$, $\mathrm{HCD}\left(3.59 \pm 0.12\left(\mathrm{ng} \mathrm{dl}^{-1}\right)\right)$ and $\operatorname{HCDCD}\left(3.60 \pm 0.12\left(\mathrm{ng} \mathrm{dl}^{-1}\right)\right)$ groups.

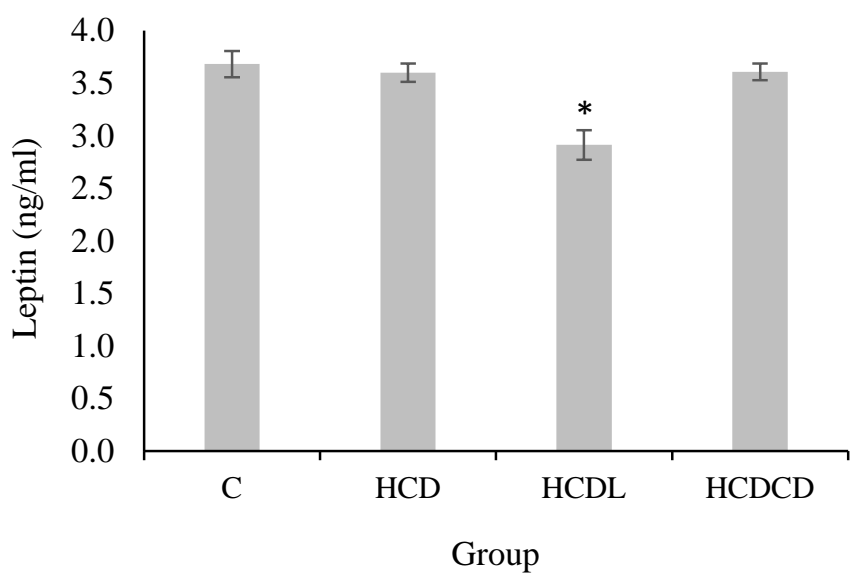

Figure 1. Leptin value (ng $\mathrm{ml}^{-1}$, mean $\pm \mathrm{SE}$ ) in $\mathrm{C}, \mathrm{HCD}$, HCDL and HCDCD groups, compared to that in HCD group.

$n=10, \quad * P<0.0001$. Leptin value in HCDL group, compared to that in other groups. Leptin value showed no significant differences within C, HCD and HCDCD groups

\section{Discussion}

The current findings showed that administration of hydroalcoholic extracts from $C$. decidua leaves and thin stems decreased serum TG and TC without altering serum LDL and HDL. Similarly, a study showed that $C$. decidua ethanolic extracts of fruits, flowers, shoots and barks decreased serum TC to 61 , 58,48 and $28 \%$ in rabbits, respectively $(23,24)$. Moreover, another study reported that oral administration of $500 \mathrm{mg} \mathrm{kg}^{-1}$ of whole fruit extract of C. decidua decreased levels of triacylglycerol and TC in Alloxan-induced diabetic rats after 30 days (25).
Findings from the present study showed that $C$. decidua extract did not affect male rat serum FBS, LDL and HDL when used in HCD. These findings were similar to those from other studies, which demonstrated that consumption of $C$. decidua extracts decreased LDL with increased serum HDL 27). These differences may be due to difference in dosage, treatment duration, experimental models, fat type or cholesterol used in HFD, or even kind of extracts of C. decidua parts. In the current study, olive oil was used as cholesterol carrier. Types of fatty acids critically affect blood lipid profile. Saturated fats increase the risk of CVD by TG and LDL increasing and HDL decreasing, while unsaturated fats act contrary (26). In Macedo et al. (27) and Leopoldo et al. (28) studies, hyper-caloric diets did not significantly change serum levels of HDL and VLDL in rats. Chahlia et al. study showed that various extracts (50\% ethanolic) of $C$. decidua significantly decreased levels of TC, TG and LDL and increased HDL in diabetic rat models for 30 days, compared to diabetic rats that did not receive $C$. decidua extracts. However, these values were significantly higher than those in nondiabetic rats (10). It seems that $C$. decidua extracts include various effects in diabetic and non-diabetic animals. Effects of $C$. decidua hydroalcoholic extracts on lipid profiles can be due to the presence of lipid or cholesterol-uptake inhibitors such as saponins and tannins in the extracts (29). Hence, C. decidua decreases lipid and cholesterol absorption, increases fecal excretion of cholesterol via bile acids and decreases reabsorption of cholesterol (30-32). The current findings revealed that hydroalcoholic extracts from $C$. decidua leaves and thin stems did not change serum FBS in HCDCD group. Although studies showed methanolic and purified extracts of $C$. decidua stems included hypoglycemic effects in diabetics and non-diabetics models (33), other studies showed that high-calorie diets or high-fat and high-cholesterol diets did not change blood glucose significantly in normal models. This is linked to increased insulin release compensatory mechanism of pancreatic beta-cells even in obese models $(34,35)$. Moreover, different results may be linked to differences in time length of study (27), extracts of Capparis spp., animal models or phenolic content of the extracts $(8,36)$. In diabetic rats, administration of fruit, flower or leave extracts of C. decidua showed significant hypoglycemic 
activities (37). These inhibitory effects can be attributed to $\alpha$-amylase and glucosidase inhibitor enzymes and alkaloid fractions $(8,29)$. Naturally, $C$. decidua fruits include nutritional fibers (31) that affect overall plasma lipids and blood glucose.

Results from the present study demonstrated that $C$. decidua extract included no effects on serum leptin in HCDCD group, compared to that it did in control and HCD groups. However, lovastatin administration decreased leptin value in HCDL group. Leptin is an adipocyte hormone that includes multiple important roles in the body such as balancing energy via sending signals to the brain based on peripheral tissue status, feeding behavior, food intake, glucose metabolism, cardiovascular system, physiological regulation of skeletal muscle angiogenesis, insulin secretion and immune system (38-40). Similarly, congenital leptin deficiency in human is associated to hyperinsulinemia and dyslipidemia. Leptin replacement therapy can improve lipid profile, glucose intolerance and weight control (41). In this study, incresed weight was seen in all groups as expected; however, gained body weight was slightly greater in $\mathrm{C}$ and $\mathrm{HCD}$ groups, compared to that in HCDCD and HCDL groups with no significant differences. It seems that administration of HCD (300 mg $\mathrm{kg}^{-1}$ ) with $C$. decidua extract or lovastatin decreases gain weight. Since increases in leptin were due to obesity (42), this can explain no differences in leptin levels in the studied groups. In one study, administration of resveratrol (200 or $400 \mathrm{mg} \mathrm{kg}^{-1}$ ) with $\mathrm{HCD}\left(500 \mathrm{mg} \mathrm{kg}^{-1}\right)$ in rabbits decreased serum leptin levels, compared to the groups that received HCD alone. Similar results were seen in body weight, blood glucose and serum insulin (43). In the present study, HCD with lovastatin decreased serum leptin level, compared to that they did in control diet and HCD with $C$. decidua extract groups. These results are supported by results from other studies $(36,44)$. However, studies have shown that atorvastatin does not affect adiponectin and leptin levels in hyperlipidemia in type- 2 diabetes $(44,45)$. These differences may be due to differences in animal models since those studies used diabetic animals.

\section{Conclusion}

In conclusion, the current study has shown that hydroalcoholic extracts from $C$. decidua leaves and thin stems decrease serum TG and TC in HFD male rats with no changes in leptin values.

\section{Acknowledgement}

The current study was financially supported by Zahedan University of Medical Sciences (Project No. 8483).

\section{Author's Contribution}

Shahraki Mohammad Reza, Badini Fereshteh, Shahraki Elham and Shahraki Ahmad Reza developed the original idea and protocols and collected data. Dashipour Ali Reza, Shahraki Mohammad Reza, and Badini Fereshteh analyzed data and wrote the manuscript.

\section{Financial disclosure}

The authors declare no competing interests.

\section{References}

1. Shahraki MR, Dehvari J, Shahrakipoor M, Shahreki E, Sharaki AR, Dashipour AR. The Effects of Anacyclus pyrethrum Alcoholic Root Extract on FSH, LH, Testosterone and Sperm Count in Diabetic Male Rats. Zahedan J Res Med Sci. 2019;21(2):e88515.

2. Naraghi T, Emam M, Ghamrizare A, Damizadeh G, Shariat A. In vitro propagation of Capparis decidua through shoot tip culture of seedlings and mature trees. Iranian Journal of Rangelands and Forests Plant Breeding and Genetic Research. 2012;20(1).

3. Gupta R. Medicinal \& Aromatic Plants 2010. CBS Publishers and Distributors, New Delhi, India.234:4991.

4. Goyal M, Nagori B, Sasmal D. Sedative and anticonvulsant effects of an alcoholic extract of Capparis decidua. Journal of natural medicines. 2009;63(4):375-9.

5. Nazar S, Hussain MA, Khan A, Muhammad G, Tahir MN. Capparis decidua Edgew (Forssk.): A comprehensive review of its traditional uses, phytochemistry, pharmacology and nutrapharmaceutical potential. Arabian Journal of Chemistry. 2020;13:1901-1916.

6. Purohit A, Vyas KB. Hypolipidaemic efficacy of Capparis decidua fruit and shoot extracts in cholesterol fed rabbits. 2005; 43(10)863-866.

7. Joseph B, Jini D. A medicinal potency of Capparis decidua-A harsh terrain plant. Res $\mathbf{J}$ Phytochem. 2011;5(1):1-13.

8. Zia-Ul-Haq M, Ćavar S, Qayum M, Imran I, Feo Vd. Compositional studies: antioxidant and antidiabetic activities of Capparis decidua (Forsk.) Edgew. International journal of molecular sciences. 2011;12(12):8846-61. 
9. Jacob B, Narendhirakannan R. Role of medicinal plants in the management of diabetes mellitus: a review. 3 Biotech. 2019;9(1):4.

10. Chahlia N. Evaluation of hypolipidaemic activity of Capparis decidua. International journal of biomedical science: IJBS. 2009;5(1):70.

11. Hajer GR, van Haeften TW, Visseren FL. Adipose tissue dysfunction in obesity, diabetes, and vascular diseases. European heart journal. 2008;29(24):2959-71.

12. Campión, Milagro, Fernández, Martínez. Vitamin C supplementation influences body fat mass and steroidogenesis-related genes when fed a high-fat diet. International journal for vitamin and nutrition research. 2008;78(2):87-95.

13. Xue Q, Chen F, Zhang H, Liu Y, Chen P, Patterson AJ, et al. Maternal high-fat diet alters angiotensin ii receptors and causes changes in fetal and neonatal rats. Biology of Reproduction. 2019;100(5):1193-1203.

14. Oosterveer MH, Van Dijk TH, Tietge UJ, Boer T, Havinga R, Stellaard F, et al. High fat feeding induces hepatic fatty acid elongation in mice. PloS one. 2009;4(6):e6066.

15. West Ce, Sullivan Dr, Katan Mb, Halferkamps Il, Van Der Torre Hw. Boys from populations with highcarbohydrate intake have higher fasting triglyceride levels than boys from populations with high-fat intake. American journal of epidemiology. 1990;131(2):27182.

16. Prieur X, Tung YL, Griffin JL, Farooqi IS, O'Rahilly S, Coll AP. Leptin regulates peripheral lipid metabolism primarily through central effects on food intake. Endocrinology. 2008;149(11):5432-9.

17. Bjorbæk C, Kahn BB. Leptin signaling in the central nervous system and the periphery. Recent progress in hormone research. 2004;59:305-32.

18. Garcia GH, Liu JN, Wong A, Cordasco F, Dines DM, Dines JS, et al. Hyperlipidemia increases the risk of retear after arthroscopic rotator cuff repair. Journal of shoulder and elbow surgery. 2017;26(12):2086-90.

19. Reseland JE, Anderssen SA, Solvoll K, Hjermann I, Urdal P, Holme I, et al. Effect of long-term changes in diet and exercise on plasma leptin concentrations-. The American journal of clinical nutrition. 2001;73(2):2405 .

20. Ahangarpour A, Oroojan AA, Heydari H, Ahmadi I. Effects of Aqueous and Hydro-Alcoholic Extracts of Bunium Persicum Seed on Insulin Secretion from Male Mouse-Isolated Langerhans Islets. The Journal of Urmia University of Medical Sciences. 2014;25(8):74251.

21. Dashti GR, Salehi M, Sajadi SE, Torabinia N. The Effect of Hydroalcoholic Extract of Dorema Aucheri on CD40 Protein Expression in Thoracic Aorta of Male White Rabbits Fed with Hypercholesterolemic Diet. Journal of Isfahan Medical School. 2012;29(166).
22. Friedewald WT, Levy RI, Fredrickson DS. Estimation of the concentration of low-density lipoprotein cholesterol in plasma, without use of the preparative ultracentrifuge. Clinical chemistry. 1972;18(6):499502.

23. Sharma I, Gusain D, Sharma A, Dixit V. Hypolipidaemic effects of Capparis decidua fruit extract $(50 \% \mathrm{EtOH})$ in cholesterol-fed rabbits. Indian Drugs. 1991;28:412-6.

24. Purohit A, Vyas K. Antiatherosclerotic effect of Caparis decidua. Fruit extract in cholesterol-fed rabbits. Pharmaceutical biology. 2006;44(3):172-7.

25. Chahlia N. Effect of Capparis decidua on hypolipidemic activity in rats. Journal of medicinal plants research. 2009;3(6):481-4.

26. Yadav P, Sarkar S, Bhatnagar D. Action Ofcapparis Deciduaagainst Alloxan-Induced Oxidative Stress And Diabetes In Rat Tissues. Pharmacological Research. 1997;36(3):221-8.

27. Singh P, Mishra G, Srivastava S, Jha K, Khosa R. Traditional uses, phytochemistry and pharmacological properties of Capparis decidua: An overview. Der Pharmacia Lettre. 2011;3(2):71-82.

28. Lorente-Cebrián S, Costa AG, Navas-Carretero S, Zabala M, Martínez JA, Moreno-Aliaga MJ. Role of omega-3 fatty acids in obesity, metabolic syndrome, and cardiovascular diseases: a review of the evidence. Journal of physiology and biochemistry. 2013;69(3):633-51.

29. Macedo I, Medeiros L, Oliveira C, Oliveira C, Rozisky J, Scarabelot V, et al. Cafeteria diet-induced obesity plus chronic stress alter serum leptin levels. Peptides. 2012;38(1):189-96.

30. Leopoldo AS, da Rocha V, Claudio E, da Silva V, Cordeiro J, Domingos L, et al. High-fat Diet-induced Obesity Model Does Not Promote Endothelial Dysfunction via Increasing Leptin/Akt/eNOS Signaling. Frontiers in Physiology. 2019;10:268.

31. Sharma B, Salunke R, Balomajumder C, Daniel S, Roy $\mathrm{P}$. Anti-diabetic potential of alkaloid rich fraction from Capparis decidua on diabetic mice. Journal of ethnopharmacology. 2010;127(2):457-62.

32. Goyal R, Grewal R. The influence of teent (Capparis decidua) on human plasma triglycerides, total lipids and phospholipids. Nutrition and health. 2003;17(1):71-6.

33. Agarwal V, Chauhan B. A study on composition and hypolipidemic effect of dietary fibre from some plant foods. Plant Foods for Human Nutrition. 1988;38(2):189-97.

34. Oakenfull D. Saponins in food - a review. Food chemistry. 1981;7(1):19-40.

35. Dangi K, Mishra S. Antihyperglycemic, antioxidant and hypolipidemic effect of Capparis aphylla stem extract in streptozotocin induced diabetic rats. Biol Med. 2010;2(4):35-44. 
36. Prada PcO, Zecchin HG, Gasparetti AL, Torsoni MrA, Ueno M, Hirata AE, et al. Western diet modulates insulin signaling, c-Jun N-terminal kinase activity, and insulin receptor substrate-1 1 ser307 phosphorylation in a tissue-specific fashion. Endocrinology. 2005;146(3): 1576-87.

37. Prentki M, Nolan CJ. Islet $\beta$ cell failure in type 2 diabetes. The Journal of clinical investigation. 2006;116(7):1802-12

38. Jéquier E, Tappy L. Regulation of body weight in humans. Physiological reviews. 1999;79(2):451-80.

39. Ahima RS, Flier JS. Leptin. Annual review of physiology. 2000;62(1):413-37.

40. Nwadozi E, Ng A, Strömberg A, Liu H-y, Olsson K, Gustafsson $\mathrm{T}$, et al. Leptin is a physiological regulator of skeletal muscle angiogenesis and is locally produced by PDGFR $\alpha$ and PDGFR $\beta$ expressing perivascular cells. Angiogenesis. 2019;22(1):103-15.

41. Dardeno TA, Chou SH, Moon H-S, Chamberland JP, Fiorenza CG, Mantzoros CS. Leptin in human physiology and therapeutics. Frontiers in neuroendocrinology. 2010;31(3):377-93.
42. Toklu H, Muller-Delp J, Sakarya Y, Oktay S, Kirichenko N, Matheny M, et al. High dietary fructose does not exacerbate the detrimental consequences of high fat diet on basilar artery function. Journal of physiology and pharmacology: an official journal of the Polish Physiological Society. 2016;67(2):205.

43. Jimoh A, Tanko Y, Ayo J, Ahmed A, Mohammed A. Resveratrol increases serum adiponectin level and decreases leptin and insulin level in an experimental model of hypercholesterolemia. Pathophysiology. 2018;25(4):411-7.

44. Von Eynatten M, Schneider JG, Hadziselimovic S, Hamann A, Bierhaus A, Nawroth PP, et al. Adipocytokines as a novel target for the antiinflammatory effect of atorvastatin in patients with type 2 diabetes. Diabetes Care. 2005;28(3):754-5.

45. Chu C, Lee J, Lam H, Lu C, Sun C, Wang M, et al. Atorvastatin does not affect insulin sensitivity and the adiponectin or leptin levels in hyperlipidemic type 2 diabetes. Journal of endocrinological investigation. 2008;31(1):42-7. 